\title{
Answer Comes from the Ghost of Christmas Past, Present, and Yet to Come*
}

\author{
Geon Ho Bahn \\ Editor-in-Chief, Korean Academy of Child and Adolescent Psychiatry
}

In the last handoff of the Orange Journal, Journal of the American Academy of Child and Adolescent Psychiatry (JAACAP), 1 December, 2017, Andrés Martin thanked several thousand reviewers and colleagues of the editorial committee during his time as editor-in-chief from 20082017. The Orange Journal was first published in 1962 and is about 30 years ahead of Journal of the Korean Academy of Child and Adolescent Psychiatry (JKACAP). Another thing that stands out in his address is the following passage " $\mathrm{Fi}$ nally, a key part of my joy as editor has been in working with the behind-the-scenes heroic editorial office trio of Mary Billingsley (managing editor), Kristine Pumphrey (assistant managing editor), and Alyssa Murphy (editorial manager)." I envy JAACAP's editorial office, which is absent from the JKACAP editorial committee.

Journal publication is a very hard job. However, the hard work is rarely recognized and rewarded. I am always apologetical to my fellow professors who work at the editorial committee. Although the iMiS Company office members are not full members of our committee and are shown to users as anonymous, I always thank the members since they assist with paper formatting and spelling.

Assessing children's mental disorders is not easy. While a lot of evaluation tools are used in the practice of child and adolescent psychiatry, child psychiatrists in Korea often use tools developed overseas rather than our own development tools. In this issue, we publish two papers on evaluation tools translated from English to Korean. Subin Park examined the Reliability and Validity of the Early Trauma Inventory Self Report-Short Form (ETISR-SF) among Korean adolescents.
This Korean version of the ETISR-SF appears to be a reliable and valid instrument for the measurement of reported childhood trauma. Soo-Young Bhang et al. translated the Behavior Problems Inventory (BPI)-01 into the Korean language and tested its validity and reliability. The authors examined the adaptability of BPI-01 to children, adolescents, and adults. Sang Soo Seo et al. completed a preliminary study to prove the effect of school-based social skills training (SST) program on peers. The SST program can have positive effects on school-based mental health services. The Ministry of Education administers the Annual National Youth Risk Behavior Survey to middle and high school students. Subin Park and Jung Hyun Lee assessed the associations of Internet use with oral hygiene based on National Youth Risk Behaviour Survey administered to 73238 students in 2010.

From 1990 to 2017, the JKACAP contributed to the publication of 67 issues. Under Professor Martin as editor-inchief over the last 10 years, the Orange Journal published 120 issues, and its impact factor exceeds 7. When I compare the JKACAP with JAACAP, I sometimes feel sad. "Why do we do this nonetheless?" I finished this editorial on Christmas Eve and did not find an answer. I guess 'the Ghost of Christmas Past, the Ghost of Christmas Present, and the Ghost of Christmas Yet to come (except Jacob Marley because I do not know him)' visited me on Christmas. The answer came to me when I flew with 'the Ghost of Christmas Yet to come.' If interested in the answer, please submit papers to the JKACAP.

*Ghosts from 'A Christmas Carol' by Charles Dickens. 